Fourth International Conference on Sustainable Construction Materials and Technologies http://www.claisse.info/Proceedings.htm

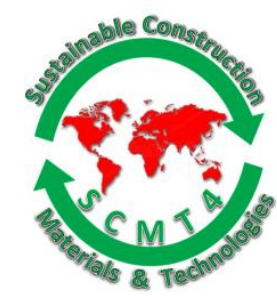

SCMT4

Las Vegas, USA, August 7-11, 2016

\title{
Long Term Engineering Properties of Fly Ash Geopolymer Concrete
}

\author{
Chamila Gunasekara ${ }^{1 a}$, David W. Law ${ }^{1 b}$ and Sujeeva Setunge ${ }^{1 c}$ \\ ${ }^{1}$ School of Civil, Environmental and Chemical Engineering, RMIT University, 124, La Trobe \\ Street, Melbourne, Victoria, 3000 Australia. ${ }^{1 a}$ Email: 〈s3404429@student.rmit.edu.au>, \\ 1bEmail:<david.law@rmit.edu.au>, ${ }^{1 c}$ Email:<sujeeva.setunge@rmit.edu.au>.
}

\begin{abstract}
Geopolymer concrete produced using $100 \%$ fly ash as the main binder is a sustainable construction material capable replacing Portland Cement (PC) concretes. At present PC production generates 5-7\% of anthropogenic $\mathrm{CO}_{2}$ emissions world-wide, but it has been estimated that this can be reduced by $26-45 \%$ by replacing PC with geopolymer concrete. In order to be confident of the real world application of geopolymer concrete and the environmental benefits it can provide, in depth knowledge is required to ensure that the fly ash used will provide acceptable long term performance from the concrete produced. A series of geopolymer concrete specimens were prepared using four different fly ashes and tested for compressive strength, flexural strength, splitting tensile strength and elasticity modulus up to one year. Microstructural development between 28 and 365 days in different geopolymers were assessed using state of the art techniques. The 365-day compressive strength, flexural strength, splitting tensile strength and elasticity modulus of four fly ash geopolymer concretes were ranged $28-88 \mathrm{MPa}, 3.9-6.3 \mathrm{MPa}, 1.8-4.7 \mathrm{MPa}$ and $10-$ $29 \mathrm{GPa}$, respectively. Compressive strength variation is attributed to degree of reactivity of the fly ash, which is primarily governed by the quantity of finer particles in the reactive amorphous phase and sodiumaluminosilicate (N-A-S-H) gel formation. The $\mathrm{CaO}$ in fly ash also reacts with alkali to produce calciumaluminosilicate (C-A-S-H) gel which provides additional strength to the concrete. The tensile strength of geopolymer concrete is governed by the gel-aggregate bond strength. Micro-cracks formed in the concrete due to high temperature curing can negatively affect the gel-aggregate bond strength. Moreover, larger crack widths lead to discontinuity and hence the formation of a less dense microstructure. This results in lower density and elasticity modulus for geopolymer concrete.
\end{abstract}

\section{INTRODUCTION}

Geopolymer concrete is an emerging construction material that can be used as a sustainable alternative to PC concrete. Whilst geopolymer can be produced from a range of alumina-silica materials, use of $100 \%$ low calcium fly ash has been the focus of considerable research due to its high level of availability and cost effectiveness (Nematollahi and Sanjayan, 2014, Law et al., 2014, Ryu et al., 2013, Diaz-Loya et al., 2011). In geopolymerization, alumina-silica oxides in fly ash react under highly alkaline conditions provided by sodium hydroxide and silicate activator, and produce amorphous N-A-S-H gel which govern the engineering properties of fly ash geopolymer concrete. A major challenge faced by the construction industry in adopting geopolymer concrete is the variability of fly ash from different sources and the effect this can have on the engineering properties of the geopolymer concrete produced (Tennakoon et al., 2014, Gunasekara et al., 2014, Diaz-Loya et al., 2011). Whilst many studies conducted to investigate the 
engineering properties of geopolymer concrete have demonstrated similarity to PC concrete, most of them were conducted using a single fly ash type for a short time period, and in each study using a mixing process unique to that study. For instance, Hardjito and Rangan (2005) found that 90-day fly ash geopolymer concrete has a comparable compressive strength and lower elasticity modulus to that of PC concrete. However, the 90-day splitting tensile strength of geopolymer concrete was found to be higher than the values recommended by the Australian Standard, AS3600 (2009). Fernandez-Jimenez et al. (2006) reported a similar findings in that fly ash geopolymer concrete developed a high compressive and flexural strength, but had a lower modulus of elasticity at 90 days. Sumajouw and Rangan (2006) suggested that fly ash geopolymer concrete is suitable for structural applications, and AS3600 (2009) can be used for the design of geopolymer concrete structures. However, Neupane et al. (2012) observed that 28-day flexural and splitting tensile strength of fly ash geopolymer concrete was about $10 \%$ higher than those predicted by AS3600 (2009) for PC concrete.

Understanding of the effect of the fly ash properties on the long term performance of the geopolymer concrete is essential to be able to construct real structures with the confidence. To date very limited attention has been given to evaluate the performance of the long term engineering properties for the wide range of fly ashes that are available across the world. Thus, this paper aims to investigate key engineering properties, such as compressive strength, flexural strength, splitting tensile strength and elasticity modulus of geopolymer concretes made with four different fly ashes with a range of chemical, physical and mineralogical properties, using the same mixing process. Observed results up to one year are reported and the variations in properties observed explained according to the current knowledge.

\section{EXPERIMENTAL INVESTIGATION}

Low calcium, class F fly ash (AS, 1998) were obtained from Gladstone, Pt.Augusta, Collie and Tarong power stations in Australia. Chemical composition, particle size distribution and mineralogical composition of fly ash were determined by X-ray fluorescence (XRF), a Malvern particle size analyser and X-ray diffraction (XRD) techniques. The data are shown in Table 1, 2 and 3. Brunauer Emmett Teller (BET) method by $\mathrm{N}_{2}$ absorption was used to determine the fly ash surface area. The alkaline liquid used in geopolymers consisted of a mixture of commercially available sodium silicate solution with a specific gravity of 1.53 and an alkaline modulus ratio (Ms) equal to 2 (where $\mathrm{Ms}=\mathrm{SiO}_{2} / \mathrm{Na}_{2} \mathrm{O}, \mathrm{Na}_{2} \mathrm{O}=14.7 \%$ and $\mathrm{SiO}_{2}=29.4 \%$ by mass), and sodium hydroxide solution (15M). Both coarse and fine aggregate were prepared in accordance with AS 1141.5 (2000a). The moisture condition of the aggregate was in a saturated surface dry condition. The fine aggregate was river sand in uncrushed form with a specific gravity of 2.5 and a fineness modulus of 3.0. The coarse aggregate was crushed basalt aggregate of two-grain sizes: $7 \mathrm{~mm}(2.58$ specific gravity and $1.60 \%$ water absorption) and $10 \mathrm{~mm}(2.62$ specific gravity and $0.74 \%$ water absorption). Demineralized water was used throughout the experiment.

Previously reported (Gunasekara et al., 2015b) optimum mix designs for each fly ash geopolymer concrete are used and shown in Table 4. The mixing of geopolymer concrete was carried out using a 90 litre concrete mixer. The dry materials (fly ash, fine and coarse aggregates) were mixed first for 4 minutes. Then activator and water were added to the dry mix and mixed continuously for another 8 minutes until the mixture was glossy and well combined. The mixture was then poured into moulds and vibrated using a vibration table for 1 minute to remove air bubbles. The inside surfaces of the moulds were coated with a high performance silicon grease to prevent the samples from sticking to the moulds surface during the heat curing process. After vibration the moulds were kept at room temperature for 1 day and then kept in a dry oven for 24 hours at $80^{\circ} \mathrm{C}$ temperature with $95 \%$ relative humidity. Moulds were removed from the oven and left to cool to room temperature before demoulding, and then the samples were kept at room temperature until being tested. 
Table 1. Chemical composition

\begin{tabular}{|l|c|c|c|c|c|c|c|c|c|c|c|}
\hline \multirow{2}{*}{ Fly ash } & \multicolumn{10}{|c|}{ by weight $(\%)$} \\
\cline { 2 - 13 } & $\mathrm{SiO}_{2}$ & $\mathrm{Al}_{2} \mathrm{O}_{3}$ & $\mathrm{Fe}_{2} \mathrm{O}_{3}$ & $\mathrm{CaO}$ & $\mathrm{K}_{2} \mathrm{O}$ & $\mathrm{TiO}_{2}$ & $\mathrm{P}_{2} \mathrm{O}_{5}$ & $\mathrm{MgO}$ & $\mathrm{Na}_{2} \mathrm{O}$ & $\mathrm{SO}_{3}$ & $\mathrm{MnO}$ \\
\hline Gladstone & 47.87 & 28.0 & 14.09 & 3.81 & 1.81 & 1.99 & 0.93 & 0.62 & 0.27 & 0.21 & 0.41 \\
\hline Pt.Augusta & 49.37 & 31.25 & 4.47 & 4.80 & 1.65 & 2.94 & 1.28 & 2.21 & 0.24 & 0.04 & 1.30 \\
\hline Tarong & 53.82 & 29.95 & 9.24 & 1.03 & 1.28 & 2.19 & 0.58 & 0.79 & 0.34 & 0.04 & 0.75 \\
\hline Collie & 75.66 & 19.0 & 1.38 & 0.30 & 1.0 & 1.83 & 0 & 0.63 & 0.03 & 0.02 & 0.15 \\
\hline
\end{tabular}

Table 2. Physical properties

\begin{tabular}{|c|c|c|c|c|c|}
\hline \multicolumn{2}{|c|}{ Properties investigated } & Gladstone & Pt.Augusta & Tarong & Collie \\
\hline \multicolumn{2}{|c|}{ BET Surface Area, $\left(\mathrm{kg} / \mathrm{m}^{2}\right)$} & 2363 & 1228 & 1876 & 1095 \\
\hline \multirow{3}{*}{ Fineness (\%) } & at 10 microns & 43.1 & 46.7 & 43.0 & 40.9 \\
\hline & at 20 microns & 61.9 & 62.1 & 63.0 & 54.6 \\
\hline & at 45 microns & 82.7 & 80.2 & 81.8 & 70.0 \\
\hline \multicolumn{2}{|c|}{ Unburnt carbon content (\%) } & 0.43 & 0.51 & 1.16 & 0.63 \\
\hline
\end{tabular}

Table 3. Mineralogical composition

\begin{tabular}{|l|l|c|c|c|c|}
\hline \multicolumn{2}{|l|}{ Mineralogical composition (\%) } & Gladstone & Pt.Augusta & Tarong & Collie \\
\hline Amorphous & 71.8 & 59.5 & 66.3 & 72.5 \\
\hline \multirow{3}{*}{ Crystalline } & Quartz & 6.8 & 29.2 & 14.8 & 18.2 \\
\cline { 2 - 6 } & Mullite & 17.9 & 7.5 & 18.9 & 8.7 \\
\cline { 2 - 6 } & Others & 3.5 & 3.8 & 0 & 0.6 \\
\hline
\end{tabular}

Table 4.Optimum mix design $\left(\mathrm{kg} / \mathrm{m}^{3}\right)$

\begin{tabular}{|c|c|c|c|c|c|c|c|c|}
\hline \multirow[t]{2}{*}{ Geopolymer } & \multirow{2}{*}{$\begin{array}{c}\text { Fly ash } \\
\text { (kg) }\end{array}$} & \multicolumn{3}{|c|}{ Aggregates (kg) } & \multicolumn{2}{|c|}{ Activator (kg) } & \multirow{2}{*}{$\begin{array}{c}\text { Added } \\
\text { Water } \\
(\mathrm{kg})\end{array}$} & \multirow{2}{*}{$\begin{array}{c}{ }^{*} \text { Water/Sol } \\
\text { id ratio }\end{array}$} \\
\hline & & Sand & $7 \mathrm{~mm}$ & $10 \mathrm{~mm}$ & $\begin{array}{l}\mathrm{Na}_{2} \mathrm{SiO}_{3} \\
\text { (Liquid) }\end{array}$ & $\begin{array}{l}\mathrm{NaOH} \\
(15 \mathrm{M})\end{array}$ & & \\
\hline Gladstone & 416 & 699 & 309 & 618 & 292 & 65 & 8 & 0.37 \\
\hline Pt.Augusta & 416 & 699 & 309 & 618 & 292 & 65 & 8 & 0.37 \\
\hline Tarong & 412 & 693 & 306 & 612 & 342 & 39 & 0 & 0.37 \\
\hline Collie & 420 & 706 & 312 & 624 & 241 & 92 & 15 & 0.37 \\
\hline
\end{tabular}

*Note: Water=Mass of water contained in $\mathrm{Na}_{2} \mathrm{SiO}_{3}, \mathrm{NaOH}$ and added water.

Solid= Mass of fly ash and solids contained in $\mathrm{Na}_{2} \mathrm{SiO}_{3}$ and $\mathrm{NaOH}$ solution.

Compressive, flexural and splitting tensile strength tests were conducted using MTS machine in accordance to AS 1012.9 (1999), AS 1012.11 (2000c) and AS 1012.10 (2000b), respectively. Elasticity modulus was determined using Tecnotest machine with reference to AS 1012.1 (2009). Microstructure development was observed using Scanning Electron Microscopy (SEM) imaging employing backscatter electron detector with $15 \mathrm{eV}$ of energy coupled with Energy Dispersive X-Ray Spectroscopy (EDS). All tests were conducted at 28, 90 and 365 days of casting. The reported test results in each specific test are an average of three samples. 


\section{EXPERIMENTAL RESULTS}

Figure 1(a) shows long term compressive strength development of four different fly ash geopolymer concretes. Compressive strength of all geopolymers tended to increase with time, but in different increment ratios, depending on the fly ash type. Gladstone geopolymer obtained the highest strength while Collie obtained the lowest at all ages, with the strength of Pt.Augusta and Tarong geopolymers between the two. With regards to the 28-day strength, both Tarong and Pt.Augusta geopolymers achieved the highest strength gain at 365 days, i.e. $44.6 \%$ (13.2MPa) and 27.4\% (10.1MPa), respectively. Gladstone geopolymer obtained the lowest strength gain $(4.94 \mathrm{MPa})$, i.e. about $95 \%$ of its 365 -day strength was achieved in the first 28 days. While Collie geopolymer obtained higher percentage of strength gain $(15.3 \%)$ than Gladstone, its strength increased by only 3.8MPa. Wallah and Rangan (2006) reported the 28-day strength of fly ash geopolymer concrete increased with age in the order of 10 to $20 \%$ when compared to the 7 -day strength. Hence, the results of this study confirmed that while heat curing enhanced the initial geopolymerization process (Bakharev, 2005, Palomo et al., 1999), strength development of geopolymer concretes continued with time. However, the order of the strength gain is strongly dependent on the properties of the raw fly ash. The density of four geopolymer concretes ranged between 2074 and $2205 \mathrm{~kg} / \mathrm{m}^{3}$, Figure 1(b), and increased with the time. This is in agreement with the literature (Diaz-Loya et al., 2011, Wardhono, 2015) though displaying lower densities than PC concrete which is characteristically cited as $2400 \mathrm{~kg} / \mathrm{m}^{3}$ (AS, 2009). All geopolymers displayed a very high, collapsed slump, thus workability is represented by the slump flow diameter. Gladstone, Pt.Augusta, Tarong and Collie geopolymer obtained the slum flow diameter as $735 \mathrm{~mm}, 550 \mathrm{~mm}, 450 \mathrm{~mm}$ and $350 \mathrm{~mm}$ respectively. This is attributed to the spherical shape of fly ash particles combined with the lubricating effect of sodium silicate solution.
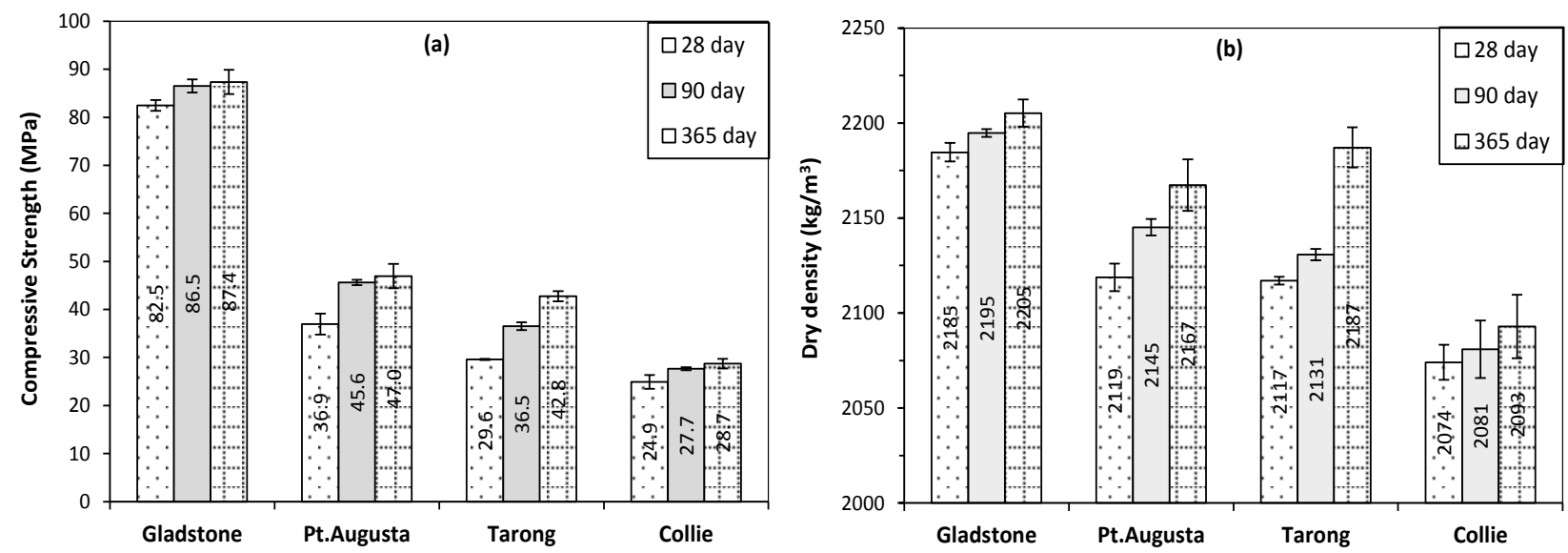

Figure 1. Long term (a) Compressive strength and (b) density development

Figure 2 shows long term flexural and splitting tensile strength development of four fly ash geopolymer concretes. Similar to compressive strength development, the flexural strength of all concretes tended to increase with time. The highest and lowest flexural strengths were displayed by Gladstone and Collie geopolymers, while the Pt.Augusta and Tarong were again in between. Flexural strength ranged from 7 to $14 \%$ of the compressive strength, compared to a range of 9 to $12 \%$ typically cited for PC concrete. DiazLoya et al. (2011) reported a similar trend but over a wider range, such that the flexural strength ranged between 9 and $26 \%$ of the compressive strength. Conversely, similar to flexural strength development, splitting tensile strength of all geopolymer concretes increased with time. Gladstone and Collie geopolymer achieved the highest and lowest splitting tensile strength with Pt.Augusta and Tarong geopolymers once more falling between the two. It is interesting to note that Pt.Augusta showed higher splitting tensile strength than Tarong, though it had lower flexural strength capacity. The splitting tensile strength ranged from 1.15 to $4.72 \mathrm{MPa}$ between 28 and 365 days, and ranged from 4 to $8 \%$ of the compressive strength. 

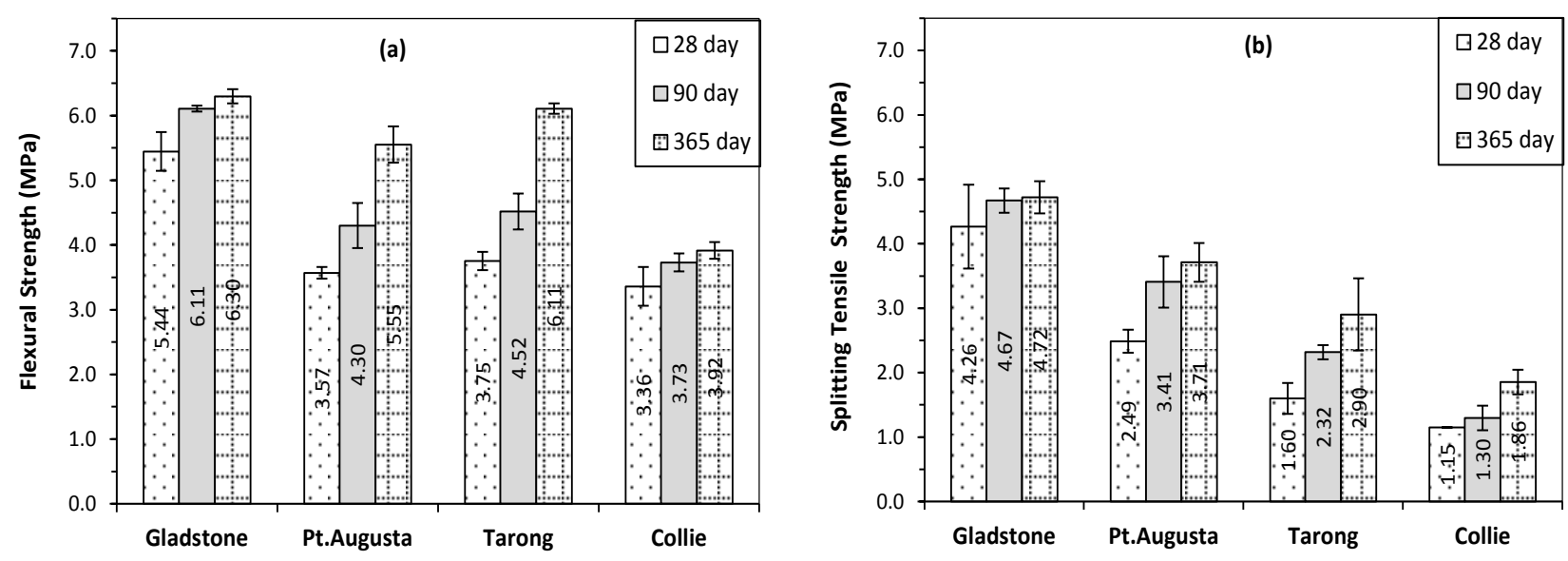

Figure 2. Long term (a) flexural strength and (b) splitting tensile strength development

The stress-strain curves shown in figure 3(a) presents the range of elasticity modulus measured in the four fly ash geopolymers. As the geopolymer concretes demonstrated brittle failure (Diaz-Loya et al., 2011), the descending branch of the stress-strain curve could not be determined in any of the tests. Each curve represents the tangent modulus of elasticity, and is ranged from 8.2 to $22.7 \mathrm{GPa}$ between Collie and Gladstone geopolymer at 28 days. Similar to the aforementioned properties, the elasticity modulus of all concretes tended to increase with time, but with different increment ratios. Gladstone geopolymer showed the highest value while Collie gave the lowest in all periods. In the first 90 days, Tarong had a similar elasticity modulus to Collie and lower than the Pt.Augusta. However, it achieved the second highest value at 365 days, gaining a two-fold increment between 90 and 365 days.
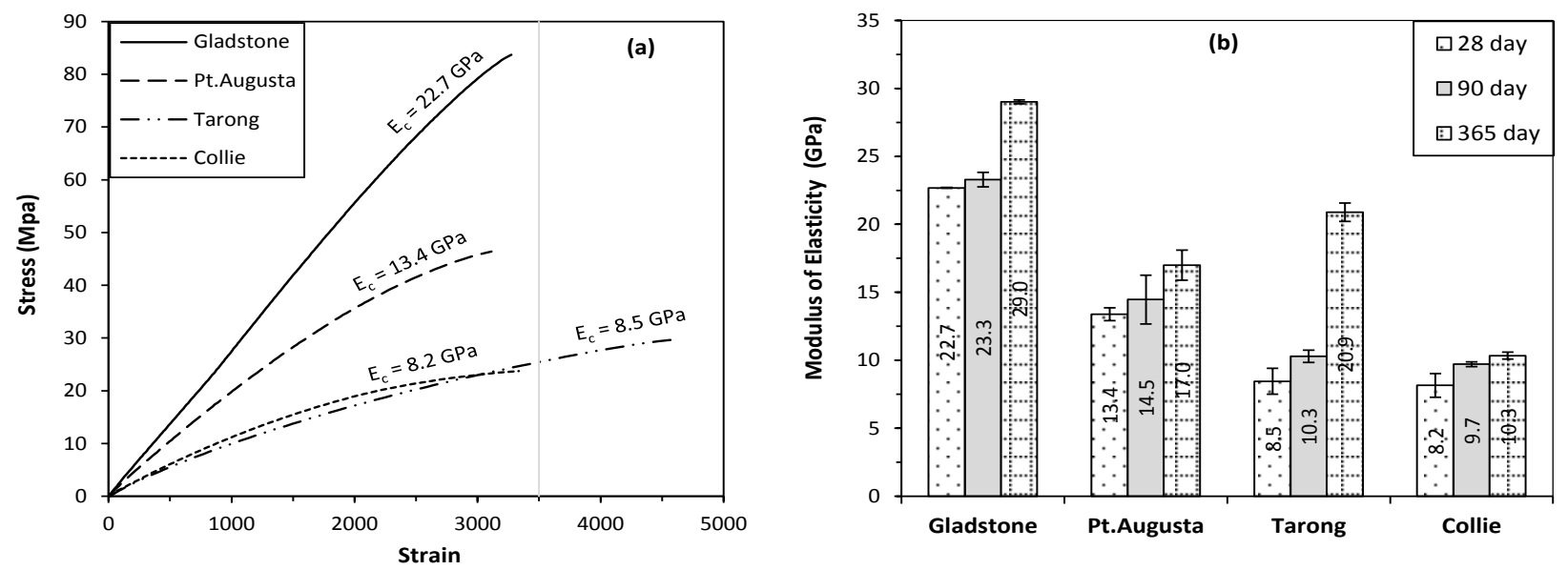

Figure 3. (a) 28-day stress-strain curve and (b) long term elasticity modulus development

\section{DISCUSSION}

In geopolymerization, alumina and silica species in fly ash react under highly alkaline conditions and produce amorphous N-A-S-H gel. This gel formation influences the nature of the matrix formed during geopolymerization, which governs the engineering properties of the geopolymer concrete. Figure 4 shows the microstructure development in the four geopolymer concretes. 

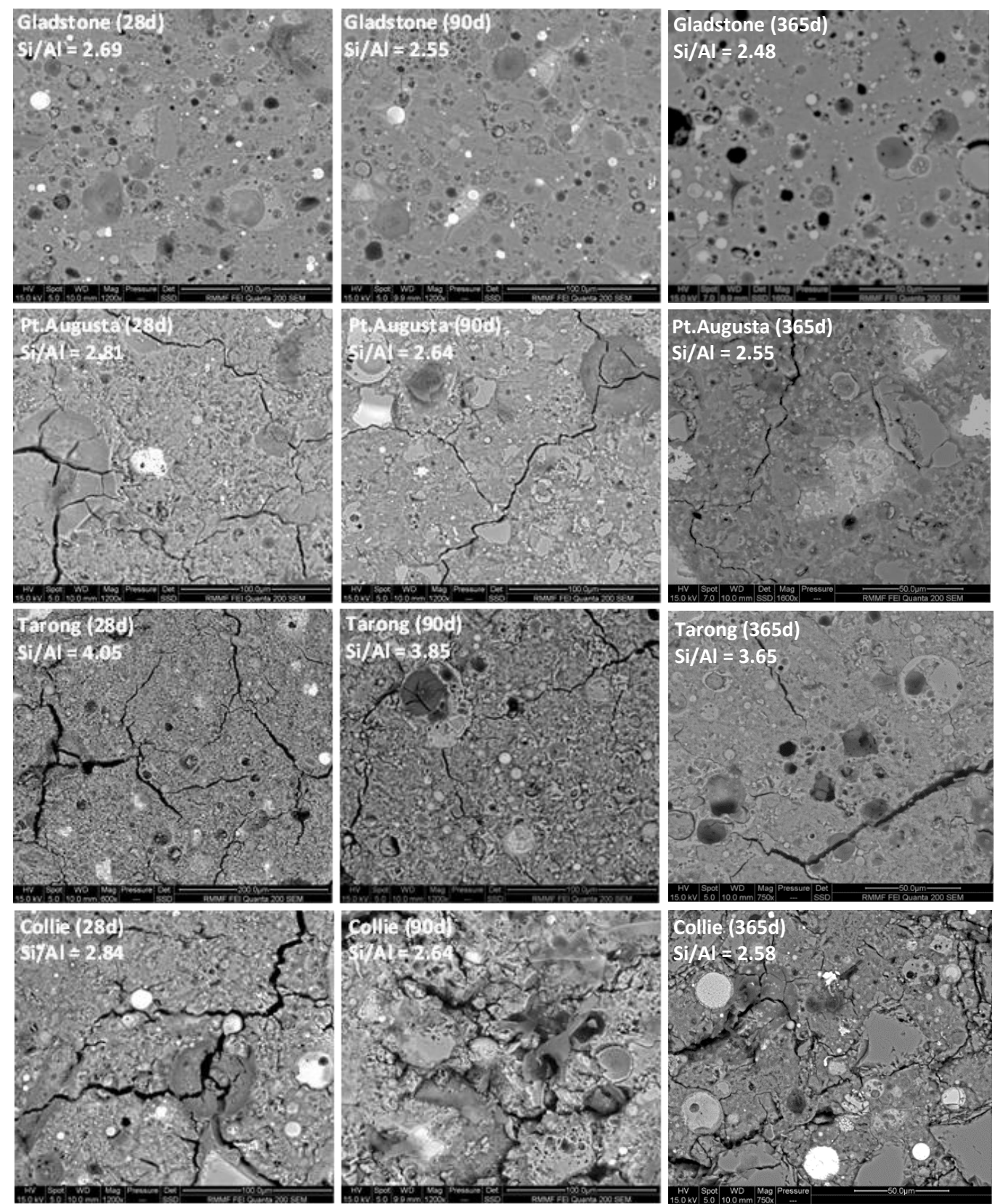

Figure 4. Long term microstructure development

In addition to the N-A-S-H gel, the microstructure consists of unreacted/partially reacted fly ash particles with the propagated micro-cracks, thus being heterogeneous in nature. The $\mathrm{Si} / \mathrm{Al}$ (atomic) ratio determines the main gel structure formed, and it ranged 2.69-2.84, 2.55-2.64 and 2.48-2.58 for all geopolymers, other than Tarong, at 28, 90 and 365 days, respectively. As such, N-A-S-H gel structure was inferred to be polysialate-siloxo (Si-O-Al-O-Si). In Tarong geopolymer, the $\mathrm{Si} / \mathrm{Al}$ ratio ranged 4.05-3.65, and the corresponding gel structure is identified as the polysialate-disiloxo ( $\mathrm{Si}-\mathrm{O}-\mathrm{Al}-\mathrm{O}-\mathrm{Si}-\mathrm{O}-\mathrm{Si}-\mathrm{O})$. In all materials, the $\mathrm{Si} / \mathrm{Al}$ ratio decreased with age. This indicates on-going geopolymerization of all concretes, with continuous gel formation along with incorporation of alumina into the silicate backbone. 
The dissolution, coagulation and N-A-S-H gel formation of geopolymers is dependent on the degree of reactivity of the fly ash. The specific surface area of fly ash coupled with the quantity of fly ash particles passing at the 10 and $20 \mu \mathrm{m}$ sieve size governs the fly ash reactivity (Gunasekara et al., 2015a). Gladstone fly ash has the highest surface area with a large amount of finer particles, especially a higher percentage passing at 10, 20 and 45 micron sieves. It also consists of a high amount of reactive alumina-silica amorphous phase. The very fine particles of amorphous phase in Gladstone thus speedily react with the alkali and produced larger amount of N-A-S-H gel. This is because alumina and silica species are mainly leached by dissolution of the amorphous phase, not the crystalline phases of fly ash (Hanjitsuwan et al., 2014), with the significant part of the alkali-fly ash reaction occurring at the particle-liquid interface (Diaz et al., 2010). This gel then diffuses covering and tightening unreacted/partially reacted particles together. Continuous gel precipitation further fills up the interior spaces and forms a strongly compacted and well condensed microstructure. This result in the high compressive strength and density of Gladstone geopolymer observed at all ages. In addition to the main gel, $\mathrm{CaO}$ reacts to form $\mathrm{C}-\mathrm{A}-\mathrm{S}-\mathrm{H}$ gel during geopolymerization. The high $\mathrm{CaO}$ content in Gladstone further adds to the compressive strength, resulting in the Gladstone concrete achieving the highest compressive strength. The combination of high $\mathrm{CaO}$, amorphous content and particles passing 10,20 and 45 micron lead to high reactivity of the Gladstone fly ash. This result in the high early strengths observed but means that little fly ash remains available for subsequent geopolymeric reaction and hence the minimal further strength increase observed.

Collie geopolymer showed a significantly different microstructure than that associated with Gladstone, Figure 4. Collie fly ash has lowest surface area with a higher fraction of coarser particles, i.e. very low level of particles passing at 10,20 and 45 micron sieves. Although it contains highest percentage of reactive amorphous phase, it mainly consists of coarse fly ash particles. Hence the reactivity and dissolution of coarser fly ash particles in alkali activator and subsequent N-A-S-H gel formation is expected to be much lower. This is confirmed by the large quantity of unreacted/partially reacted fly ash particles that can be seen in the microstructure. These composites and the interface between them and geopolymer matrix have a significant bearing on the overall strength of the concrete (Steveson and Sagoe-Crentsil, 2005). Both the unreacted particles and the interface can be an area of weakness thus the large quantity observed in the Collie geopolymer concrete are attributed as the reason for the low compressive strengths at all ages.

Both Pt.Augusta and Tarong had what could be regarded as moderate compressive strength development. Similar to Gladstone, both materials contained a large amount of finer particles, but a lower surface area and amorphous percentage than Gladstone. The properties of these two materials are thus governed the rate of N-A-S-H gel formation and heterogeneous nature of the microstructure coupled with the quantity of unreacted composites. Pt.Augusta fly ash has the highest $\mathrm{CaO}$ content while Tarong has the lowest. The $\mathrm{C}$ A-S-H gel produced by this additional $\mathrm{CaO}$ in the Pt.Augusta is identified as one reason for the higher strength observed compared to the Tarong, although it has a lower surface area. Tarong fly ash also contains more unburnt carbon content. The unburnt carbon acts as an inert particulate and absorbs activator solution (Diaz et al., 2010). Hence, the higher unburnt carbon content in Tarong also negatively affected its compressive strength development. Conversely, not like Gladstone, both geopolymer concretes showed a higher strength development between 28 and 365 days. Presumably the lower surface area of two fly ashes led to a lower initial dissolution of alumina-silicate species. However, this dissolution is continued over time and produced more geopolymeric gel that gives the higher strength development for both Pt.Augusta and Tarong. The microstructure difference observed of Tarong between 90 and 365 days indeed give an evidence for this continuous dissolution.

The flexural and splitting tensile strengths of geopolymer concrete are dependent on the gel-aggregate bond strength. This is itself dependent on micro-crack propagation in the microstructure, especially in the gelaggregate zone, during high temperature curing. Gladstone geopolymer concrete produced a denser microstructure with little micro-cracks, Figure 4. In Gladstone the gel bound the aggregates together and formed very strong bond between them. Hence, the strong gel-aggregate bond coupled with the small 
number of crack propagation resulted in the high flexural and splitting tensile strengths for Gladstone concrete. In contrast, Collie geopolymer had a large number of micro-cracks which separated the microstructure into several small pieces creating discontinuities in the matrix, Figure 4. This resulted in a less dense structure. Unreacted fly ash particles are spherical and a propagating crack would require a lot of energy to break them. As such, cracks will preferentially changes their paths and continue their way across the gel binder combining micro-cracks together. This is reflected in the increased crack width and discontinuity identified under microscopic analysis. Thus, the high quantity of cracks propagated in the geopolymerization weakened the bond between gel-aggregate zones in Collie, resulting in the lowest tensile strengths achieved at all ages.

Tarong fly ash contains a high quantity of unburnt carbon which understood to weaken the bonding with aggregates. It further contains high amorphous $\mathrm{SiO}_{2}$ content, which is expected to result in more $\mathrm{Si}^{+4}$ being leached into the activator. The optimum Tarong mix also required a higher sodium silicate concentration than other mixes. Fernandez-Jimenez et.al (2006) has reported that the presence of excess $\mathrm{Si}^{+4}$ in the alkaline activator solution has a substantial negative effect on the gel-aggregate bond. Hence, the excess of $\mathrm{Si}^{+4}$ in addition to the micro-crack propagation observed is hypothesised as the cause of the lower splitting tensile strength of Tarong compared to Pt.Augusta geopolymer. However, it is interesting thing noted in the Tarong is higher flexural strength than Pt.Augusta. This behaviour can be explained by the influence of the loading arrangement on tensile stress distribution. The splitting tensile test produced biaxial stress, but significantly a greater volume of the specimen is subjected to the tensile stress which is dependent on the gel-aggregate bond. The remaining smaller volume is under horizontal compressive stress. In contrast, the maximum fibre stress reached in the flexural strength test is higher than the splitting strength because the propagation of a crack is blocked by less stressed material near to the neutral axis. Thus the energy available is below that necessary for the formation of new crack surfaces, resulting higher resistance to the tensile failure. Tarong Geopolymer showed a higher strain than Pt.Augusta, figure 3(a), thus excessive bending and deflection can be achieved. This is hypnotized as resulting higher resistance to the flexural failure in Tarong than Pt.Augusta.

All geopolymer concretes in this study showed a much lower elasticity modulus than PC concrete (AS, 2009). Liu et.al. (2014) reported that the pore volume and elasticity modulus have a linear relationship, as the density of the geopolymer concrete increases the elasticity modulus also increases. However, in this study all geopolymer concretes showed lower densities than PC concrete. The forming of discontinuities in the internal microstructure due to micro-crack propagation under high temperature curing is believed to have significantly influenced the elasticity modulus changes in the four geopolymer concretes. The dense microstructure, with the least number of micro-cracks, would explain the higher elasticity modulus of Gladstone concrete. The intensity of crack propagation and corresponding larger crack widths observed in Collie geopolymer correlate with the lower elasticity modulus. The variation in the elasticity modulus in other two geopolymers also correlated well with their microstructure and crack propagation.

\section{CONCLUSION}

Based on the results of the experimental study, the following conclusions can be made:

- The 365-day compressive strength of four different fly ash geopolymer concretes ranged between 28 and $88 \mathrm{MPa}$. Compressive strength of all concretes increased with time, but in different increment ratios. The order of 5 to $45 \%$ strength gain is obtained by four concretes at 365 days, when compared to the corresponded 28-day strength.

- This compressive strength variation and its development are attributed to the reactivity of fly ash, mainly governed by the quantity of finer particles in reactive amorphous phase. The $\mathrm{CaO}$ in fly ash produce $\mathrm{C}$ A-S-H gel which provides additional compressive strength to the concrete. 
- The 365-day flexural strength and splitting tensile strength of four geopolymer concretes ranged from 3.92 to $6.3 \mathrm{MPa}$ and 1.86 to $4.72 \mathrm{MPa}$, respectively. Moreover, the 365-day elasticity modulus of geopolymer concretes changed between 10.3 and 29.0GPa.

- Flexural and splitting tensile strength of geopolymer concrete is dependent on the gel-aggregate bond strength. The micro-crack propagation during geopolymerization under high temperature curing negatively affects the gel-aggregate bond. In addition, the unburnt carbon content in raw fly ash and an excess of $\mathrm{Si}^{4+}$ ions leached into the activator solution can further weaken the gel-aggregate bond, resulting in a lower tensile strength.

- Compacted and well condensed microstructure has fewer cracks where higher energies are required to initiate and propagate cracks. The degree of the fly ash reactivity and continuous gel formation govern the density of the gel microstructure. In contrast, a higher number of unreacted fly ash particles indirectly cause an increase in the crack width. This results in the creation of discontinuities leading to the forming of a less dense microstructure. This, in turn, produces a lower density and elasticity modulus of geopolymer concrete.

\section{ACKNOWLEDGEMENT}

The authors wish to express their thanks to Cement Australia Pty Ltd. and Flyash Australia Pty Ltd for the supply of fly ash. PhD scholarship provided by the school of Civil, Environmental and Chemical Engineering of RMIT is gratefully acknowledged.

\section{REFERENCES}

AS 3582.1 (1998). "Supplementary cementitious materials for use with portland and blended cement". Standards Australia, 1-13.

AS 1012.9 (1999). "Method of testing concrete, Method 9: Determination of the compressive strength of concrete specimens.". Standards Australia, 1-12.

AS 1141.5 (2000a). "Methods for sampling and testing aggregates.". Standards Australia, 1-8.

AS 1012.10 (2000b). "Methods of testing concrete - Determination of indirect tensile strength of concrete cylinders (Brasil or splitting test)". Standards Australia, 1-5.

AS 1012.11 (2000c). "Methods of testing concrete - Determination of the modulus of rupture". Standards Australia, 1-5.

AS 3600 (2009). "Concrete structures". Standards Australia, 1-208.

Bakharev, T. (2005). "Geopolymeric materials prepared using Class F fly ash and elevated temperature curing". Cement and Concrete Research, 35, 1224-1232.

Diaz-Loya, E. I., Allouche, E. N. \& Vaidya, S. (2011). "Mechanical Properties of Fly-Ash-Based Geopolymer Concrete". ACI Materials Journal, 108, 300-306.

Diaz, E. I., Allouche, E. N. \& Eklund, S. (2010). "Factors affecting the suitability of fly ash as source material for geopolymers". Fuel, 89, 992-996.

Fernandez-Jimenez, A. M., Palomo, A. \& Lopez-Hombrados, C. (2006). "Engineering properties of alkaliactivated fly ash concrete". ACI Materials Journal, 103, 106-112.

Gunasekara, C., Law, D. W., Setunge, S. \& Sanjayan, J. G. (2015a). "Zeta potential, gel formation and compressive strength of low calcium fly ash geopolymers". Construction and Building Materials, 95, 592-599. 
Gunasekara, M. P. C. M., Law, D. W. \& Setunge, S. "Effect of composition of fly ash on compressive strength of fly ash based geopolymer mortar". 23rd Australasian Conference on the Mechanics of Structures and Materials (ACMSM23), 9-12 December 2014 Byron Bay, Australia. 113-118.

Gunasekara, M. P. C. M., Law, D. W. \& Setunge, S. "A comparative study of durability characteristics and microstructure of five different fly ash based geopolymer concretes". 14th International Congress on the Chemistry of Cement (ICCC 2015), 13-16 October 2015b Beijing, China. 1-12.

Hanjitsuwan, S., Hunpratub, S., Thongbai, P., Maensiri, S., Sata, V. \& Chindaprasirt, P. (2014). "Effects of $\mathrm{NaOH}$ concentrations on physical and electrical properties of high calcium fly ash geopolymer paste". Cement and Concrete Composites, 45, 9-14.

Hardjito, D. \& Rangan, B. V. (2005). "Development and properties of low-calcium fly ash-based geopolymer concrete". Research Report GC 1, Curtin University of Technology, Perth, Australia, 1-103.

Law, D. W., Adam, A. A., Molyneaux, T. K., Patnaikuni, I. \& Wardhono, A. (2014). "Long term durability properties of class F fly ash geopolymer concrete". Materials and Structures, 1-11.

Liu, M. Y. J., Alengaram, U. J., Jumaat, M. Z. \& Mo, K. H. (2014). "Evaluation of thermal conductivity, mechanical and transport properties of lightweight aggregate foamed geopolymer concrete". Energy and Buildings, 72, 238-245.

Nematollahi, B. \& Sanjayan, J. (2014). "Effect of different superplasticizers and activator combinations on workability and strength of fly ash based geopolymer". Materials \& Design, 57, 667-672.

Neupane, K., Baweja, D., Shrestha, R., Chalmers, D. \& Sleep, P. (2012). "Mechanical properties of geopolymer concrete: Applicability of relationships defined by as 3600". Concrete In Australia, 40, 1, Concrete Institute of Australia, 50-56.

Palomo, A., Grutzeck, M. W. \& Blanco, M. T. (1999). "Alkali-activated fly ashes: A cement for the future". Cement and Concrete Research, 29, 1323-1329.

Ryu, G. S., Lee, Y. B., Koh, K. T. \& Chung, Y. S. (2013). "The mechanical properties of fly ash-based geopolymer concrete with alkaline activators". Construction and Building Materials, 47, 409-418.

Steveson, M. \& Sagoe-Crentsil, K. (2005). "Relationships between composition, structure and strength of inorganic polymers". Journal of Materials Science, 40, 4247-4259.

Sumajouw, M. \& Rangan, B. V. (2006). "Low-calcium fly ash-based geopolymer concrete: Reinforced beams and columns". Research Report GC 3, Curtin University of Technology, Perth, Australia, 1-121.

Tennakoon, C., Nazari, A., Sanjayan, J. G. \& Sagoe-Crentsil, K. (2014). "Distribution of oxides in fly ash controls strength evolution of geopolymers". Construction and Building Materials, 71, 72-82.

Wallah, S. \& Rangan, B. V. (2006). "Low-calcium fly ash-based geopolymer concrete: Long-term properties". Research Report GC 2, Curtin University of Technology, Perth, Australia, 1-107.

Wardhono, A. (2015). "The Durability of Fly Ash Geopolymer and Alkali-Activated Slag Concretes." Ph.D. Thesis, RMIT University, 1-326. 